\title{
HIDDEN VACANCY RATE AS A PART OF OFFICE MARKET DYNAMICS IN SELECTED POLISH CITIES
}

\author{
Krzysztof Nowak \\ Faculty of Economics \\ University of Rzeszów \\ e-mail:krnowak@ur.edu.pl
}

\begin{abstract}
The hidden vacancy rate reflects the adjustments of the market vacancy rate that may occur in the future, in the event of a change in market conditions. Its occurrence results from the fact that the current level of rented office space reflects the demand based on past levels of rent and past predictions of changes in the tenants' demand for space during the term of the lease. Thus, the level of total, occupied office space at given moment does not result from demand based on the current market rent. This is the result of the duration of lease agreements concluded for more than one period. The hidden vacancy rate is also related to the costs of searching for office space that meets the specific criteria of tenants, removal costs and office space adaptation costs. The hidden vacancy rate cannot be observed in the market, but can be determined based on available market data.

The article presents the concept of a hidden vacancy rate. Next, the presented theory was used to determine the dynamics of the hidden vacancy rate in a narrow and broad approach in the market of modern office space in Warsaw, Krakow, Wroclaw and Poznan. The obtained results were compared to two mature office space markets in Western Europe. The study shows differences in the formation of the hidden vacancy rate on the market characterized by a relatively large total stock of available office space in relation to markets being at an earlier stage of development.
\end{abstract}

Keywords: office space market, hidden vacancy rate, vacancy rate and rent.

JEL Classification: $R 30, R 33, R 39$.

Citation: Nowak, K. (2020). Hidden vacancy rate as a part of office market dynamics in selected polish cities. Real Estate Management and Valuation, 28(1), 1-12.

DOI: https://doi.org/10.2478/remav-2020-0001

\section{Introduction}

The accession of Poland to the European Union in 2004 and connected inflow of foreign capital played a crucial role in changes occurring on the Polish real estate market. These changes concerned not only the housing market, but were also significant for commercial market, including the office space market. The increase in the supply of modern office space in the first years after the political and economic transformation, which began in 1989, was noticeable mainly in Warsaw. Poland's accession to the European Union, however, was an impulse for the development of the office market in other cities, primarily Krakow, Wroclaw, Poznan and the Tri-City. A systematic inflow of foreign investments from business service sectors and business processes outsourcing into these cities was a key factor leading to the increase in the supply of office space in these regional markets.

The intensive development of the office space market in recent years suggests focusing greater attention to this element of the real estate market, which, in Poland, has not yet been a subject of indepth scientific research, as it has in Western Europe or in the United States. The aim of this article is 


\section{S sciendo}

to present the concept of the hidden vacancy rate, which is an element of the dynamics of the office space market. The article presents the hidden vacancy rate, determined by a narrow and broad approach, for four major office space markets in Poland. The study is to answer the question of whether the fluctuations of the time series of the hidden vacancy rate in the market of modern office space in Warsaw and regional markets in Krakow, Wroclaw and Poznan are similar to those from selected office markets of countries in Western Europe. In this context, the article may serve as a contribution to the discussion on the differences in the dynamics of office space markets characterized by a high office space stock in relation to those at an earlier stage of development.

\section{Literature review}

The analysis of the literature indicated that the term "hidden vacancy rate", according to the best of our knowledge, was first used by Hendershott et al., though in the context of the area of non-rented properties and, at the same time, not being put up on the the market (Hendershott et al., 1999). In turn, De Francesco used this term in relation to fluctuations of the average office space per employee resulting from cyclical fluctuations in that market (De Francesco 2008). It was only Englund et al., in the publication concerning the office space market in Stockholm, who gave today's meaning to hidden vacancy rate. They stated that, at any given time, the space occupied by tenants may differ from the size of the demand for office space at the current market level of rent (Englund et al., 2008). This means that the "current rented space level reflects demand based on past rental rates and past expectations of space needs over the course of the contract, rather than on demand based on the current rent and expectations about future rent" (Englund et al., 2008, p. 96).

The existence of hidden vacancy rate results from several factors. The first is the duration of lease contracts. The period which office space lease agreements are concluded for is usually specific to a given local market. Nevertheless, such contracts are usually concluded for several or many periods. Hendershott et al. stated that, in the London office market, contracts were typically concluded for 25 years until 1990, after which the duration shortened to an average of 10-15 years around 2006 (Hendershott et al., 2010). The change in the terms of contracts then usually occurred every 5 years, with rent negotiated only upwards. The rent was then set at the higher of the two levels: the current market rent or the unchanged rent previously stated in the contract. In Polish conditions, lease agreements are usually concluded for a few years, and tenants have the option of renegotiating rental rates and changing the occupied space after the expiry of the time for which the contract was agreed. It is rare for a rental agreement to include options to change rent after a certain period of time (e.g. several years), before the end of the contract period.

Other reasons for the existence of the hidden vacancy rate are the cost of searching for office space that meets the tenants' specific criteria and removal costs. What's more, both the tenant and the landlord can also bear the costs associated with the adaptation of office space. The occurrence of the aforementioned costs means that, at a given moment, most tenants will not decide to change the occupied space. They will be bound by contracts concluded in past market conditions, with past rental rates. Hendershott et al. pointed out that the hidden vacancy rate reflects the differences between the rented area and the equilibrium demand (Hendershott et al., 2010). The latter is a demand that "would exist if all tenants were paying the current lease rent and had current expectations of space needs" (Hendershott et al., 2010, p. 90). The existence of hidden vacancy rate in that case means that fluctuations in market rents and the market vacancy rate are not close to the expected negative correlation. They do not constitute "mirror images" of each other, as they would if all tenants were paying current market rental rates at a given moment. In this context, it should be noted that changes in free, unoccupied space, available in the market, may therefore occur not only as a result of both supply and demand shocks. The market vacancy rate may also fluctuate as a result of the expiration of subsequent lease agreements and adjustment of office space consumption by tenants.

Englund et al., when drawing formulas for the hidden vacancy rate, followed the assumption (Englund et al., 2008, p. 96):

$$
D(R, E A)=\left(1-v_{t}-v h_{t}\right) * S U
$$

where: $D(R, E A)$ - demand as a function of rent and economic activity, $v_{t}$ - market vacancy rate, $v h_{t}$ - hidden vacancy rate, $S U$ - total office space stock available in the market. Therefore, they modified the approach introduced to the commercial real estate market research based on the error correction model presented by Hendershott et al. (Hendershott et al., 2002a), which was later also 
used to model panel data (Hendershott et al., 2002b). An element representing the hidden vacancy rate was added to the equation in which demand is equal to the rented office stock. The error correction model consists of two equations: long-term and short-term, which is based on the increments of the processes studied (Kośko et al., 2007, p. 356). The time series of variables used in the long-term equation should be characterized by the presence of a cointegrating relation and, unlike the series of short-term equations, should not be stationary. The long-term equation reflects long-term dependencies that take place in the market, which are understood as a state of equilibrium. In turn, the short-term equation describes adjustments taking place in the short period. The estimation of coefficients of both equations can be based on the method of least squares, i.e. the classic concept of linear regression.

After appropriate transformations, Englund et al. presented the final formulas that were used to determine the hidden vacancy rate according to the broad and narrow approach. Under the first measure, the equation for the hidden vacancy rate is as follows:

$$
\ln X b=\lambda_{R}\left(\ln R^{*}-\ln R\right)+\ln (1-v)-\ln \left(1-v^{*}\right)
$$

where: $X b$ - hidden vacancy rate according to the broad approach, $\lambda_{R}$ - absolute value of price elasticity of demand, $R^{*}$ - equilibrium rent (rent determined based on the long-term equation), (ln $R^{*}$ $\ln R$ ) - residuals from the long-term equation of the error correction model, $v$ - market vacancy rate, $v^{*}$ - natural vacancy rate ${ }^{1}$ (Englund et al., 2008, p. 97). Hendershott et al. also used this formula to set the hidden vacancy rate for the office space market in the City of London, though slightly modifying it. In place of the last two variables representing log values, they used the market vacancy rate and the natural vacancy rate (Hendershott et al., 2010, p. 90) respectively. In a narrow perspective, Englund et al. determined the hidden vacancy rate by the following formula (Englund et al., 2008, p. 97):

$$
\ln X n=\lambda_{R}(\ln R a v g-\ln R)
$$

where: $X n$ - hidden vacancy rate according to the narrow approach, Ravg-average rent of all lease agreements being in force in the market, $R$ - current market rent. In the narrow approach, the only reason for the difference between rented stock of office space and the equilibrium demand at the current level of rental rates, is the fact that contracts are concluded not for one, but for many periods. In this case, the hidden vacancy rate is a function of the ratio between demand at the average rent from all lease agreements in force and the demand at the current market rent at which new lease agreements are currently concluded. Englund et al. also indicated a relation integrating both measures of the hidden vacancy rate (Englund et al., 2008, p. 97), pointing out that:

$$
\ln X b=\ln X n+\lambda_{R}\left(\ln R^{*}-\ln R a v g\right)+\ln (1-v)-\ln \left(1-v^{*}\right)
$$

The above formula emphasizes the positive relationship between the two measures of the hidden vacancy rate. The difference in values achieved by the hidden vacancy rate in the two approaches results from the costs of searching for and adapting the office space as well as costs of moving. These are included in the broad approach, but not in the narrow approach.

\section{Data and Methods}

\subsection{Data}

Referring to time series of rent, we need to point out that research of office market using effective real rent is rare (STEVENSON, 2007), which results from the problematic way of acquiring such data. Some authors used, in their research, the real rent determined with the use of the hedonic index (Brounen \& Jennen, 2009a), while some tried to obtain an effective rent based on the created formula (Hendershott et al., 2010). In this article, the quarterly rental time series consist of rent expressed in euros, payable

\footnotetext{
${ }^{1}$ The natural vacancy rate is based on the concept of a natural unemployment rate. In the simplest approach, the natural vacancy rate is the vacancy rate in the office space market, which is in a state of equilibrium (McCartney, 2010, p.11). It should be noted that, on the office space market, there is always certain amount of space which remains non rented, even when the market can be described as the landlord's market. Sivitanides (1997) pointed out that two dominant approaches to defining the natural vacancy rate can be found in the literature. According to the first, the natural vacancy rate is the effect of tenant turnover. According to the second approach, the natural vacancy rate should be treated as an optimal reserve of vacant space, which allows for maximizing the expected profit of landlords. In this approach, the natural vacancy rate depends on the expectations of building owners or managers as to the demand for office space and the marginal cost of having free space.
} 
monthly in advance for the lease of one sq $\mathrm{m}$. of office space. Time series of rent are based on data of asking rents specified as prime rents. Thus, rental rates refer to space in class A office buildings, in the best locations on the market, for medium-sized lease agreements (basically from 500 to 1,000 sq m.) of typical office space. The rental rates were not modified to include issues such as rent-free periods, other incentives for tenants or taxes. The above time series have been inflation adjusted using data on HICP inflation for the euro area. For regional markets (Krakow, Wroclaw, Poznan), rent time series cover the entire city area. In the case of Warsaw, they concern the area of the Central Business District. We sought to obtain the longest possible time series, which can obviously positively affect the quality of the study from an econometric perspective. However, this approach does not always allow the use of data covering exactly the same territorial scope. This issue has been repeatedly raised in the literature, and similar data has been used many times, even in studies on the office space market in London, which is probably the most thoroughly researched office market in the world (Hendershott et al., 2010).

Barriers to the availability of supply data directly cause the variety of the time series that were used in research by individual authors. An example in this respect may be the use of a time series of total market space built based on a model that uses series of existing office stock, data on completed office buildings, as well as space in demolished buildings (MOUZAKIS \& RICHARDS, 2007). Another example may be time series of total office space available on the market, constructed by adding changes in net area to the market stock in the first year of analysis, i.e. the sum of new office space and demolitions (ENGLUND et al., 2008). In the literature, one can also find examples of using a time series of increments of office space available on the market in a given period (BROUNEN \& JENNEN, 2009a). Many authors have used time series of the rented, occupied share of the total office area available on the market, which may be arguable (ADAMS \& FÜsS, 2012). However, in our opinion, to create time series reflecting supply - if such data is available for the appropriate time period - the data regarding the entire available office space on the market should be used in the first place. This approach has been used in past studies (MCCARTNEY, 2012; BROUNEN \& JENNEN, 2009b). Accordingly, in this study, time series of the total stock of office space available on the market have been used to estimate supply variables. The time series of rent used in the article and the time series of total office stock were made available to the author by the Polish branch of Cushman \& Wakefield.

Demand variables used in studies based on the error correction model were most often formulated on the basis of employment measures in the so-called FIRE sectors (finance, insurance, real estate) or the business services sector, which the demand for the rental of office space traditionally largely derives from. Data collected by the Central Statistical Office allow for the formulation of similar employment measures. However, in 2004 and 2007, significant transformations of the Polish Classification of Activities took place, which made it impossible to create a coherent time series, characterized by the required length, representing average employment or the number of people working in selected sections of the economy. In connection with the above, more aggregated and wider data were used to determine demand variables. They represent different employment measures in individual cities and can be used to reflect changes in the demand for office space at the local level. The usefulness of two kinds of data for each city have been verified: workers in the enterprise sector and average employment in the enterprise sector. For each local office market, two long-term equations using these series were formulated as part of the error correction model. While choosing the final form of the equation and thus the time series reflecting the demand variable, we were guided by the econometric features of each equation (better coefficient of determination and/or higher statistical significance of individual variables). Time series with similar specifics have already been used to model the modern office space market (KE \& WHITE, 2013). The use of data of a broader nature also seems to be theoretically justified as it makes it possible to avoid errors that may result from narrowing the impact of only few selected sectors of the economy on the office space market (BRUNEAU \& CHERFOUH, 2015) when choosing time series.

Characteristics of time series used in the study

Table 1

\begin{tabular}{|c|c|c|c|c|}
\hline $\begin{array}{c}\text { Error } \\
\text { correction } \\
\text { model }\end{array}$ & Model 1 & Model 2 & Model 3 & Model 4 \\
\hline Office space & Warsaw & Krakow & Wroclaw & Poznan \\
\hline
\end{tabular}




\begin{tabular}{|c|c|c|c|c|}
\hline market & & & & \\
\hline Time series & Quarterly & Quarterly & Quarterly & Quarterly \\
\hline Time period & Q1 2005 - Q1 2016 & Q4 2008 - Q1 2016 & Q4 2008 - Q1 2016 & Q4 2008 - Q1 2016 \\
\hline $\begin{array}{c}\text { Time series } \\
\text { of rent }\end{array}$ & $\begin{array}{c}\text { Rent in EUR / sq } \\
\text { m. / month }\end{array}$ & $\begin{array}{c}\text { Rent in EUR / sq } \\
\text { m. / month }\end{array}$ & $\begin{array}{c}\text { Rent in EUR / sq } \\
\text { m. / month }\end{array}$ & $\begin{array}{c}\text { Rent in EUR / sq } \\
\text { m. / month }\end{array}$ \\
\hline $\begin{array}{l}\text { Time series } \\
\text { of demand }\end{array}$ & $\begin{array}{l}\text { Workers in the } \\
\text { enterprise sector in } \\
\text { thousands }\end{array}$ & $\begin{array}{l}\text { Average } \\
\text { employment in the } \\
\text { enterprise sector in } \\
\text { thousands }\end{array}$ & $\begin{array}{l}\text { Average } \\
\text { employment in the } \\
\text { enterprise sector in } \\
\text { thousands }\end{array}$ & $\begin{array}{c}\text { Average } \\
\text { employment in } \\
\text { the enterprise } \\
\text { sector in } \\
\text { thousands }\end{array}$ \\
\hline $\begin{array}{l}\text { Time series } \\
\text { of supply }\end{array}$ & $\begin{array}{l}\text { Total office market } \\
\text { stock in sq m. }\end{array}$ & $\begin{array}{l}\text { Total office market } \\
\text { stock in sq } \mathrm{m} \text {. }\end{array}$ & $\begin{array}{l}\text { Total office market } \\
\text { stock in sq } \mathrm{m} \text {. }\end{array}$ & $\begin{array}{c}\text { Total office } \\
\text { market stock in sq } \\
\mathrm{m} .\end{array}$ \\
\hline
\end{tabular}

Source: own study.

\subsection{Methods}

The presented data served to formulate four equations expressing long-term dependencies based on the error correction model. The time series used for constructing these equations (rent, total office space stock and employment) are in the form of natural logarithms. The time series of data used in each of the formulated long-term equations were subjected to stationarity evaluation using the ADF test. Moreover, the Johansen test was used to verify cointegration between variables used in the longterm equation. Obtained results presented in Table 2 and Table 3 in the Appendixes, allowed for the continuation of the study. Long-term equations of error correction models for individual cities are presented in Table 4 in the Appendixes. The price elasticity of demand and the residuals obtained on the basis of these equations were used to determine the hidden vacancy rate. The price elasticity of demand was determined as the inverse of the coefficient of the supply variable (HENDERSHOTT et al., 2002a).

As McCartney noted in the literature, the natural vacancy rate was traditionally determined based on the evaluation of the coefficients of the equation, in which the change in rent was explained by the market vacancy rate (MCCARTNEY, 2010, p. 15). The value of the natural vacancy rate in this approach was the relation of a constant from the above equation, with an altered sign and coefficient evaluation of a variable representing the market vacancy rate. In order to determine the natural rate of vacancy, we formulated four analogous equations corresponding to Models from 1 to 4 . In each of the equations, except for the office space market in Poznan, there were econometric problems, related to the significance of the explanatory variable and the $\mathrm{F}$ statistics, and the probability value corresponding to it. Moreover, the determined equations were characterized by low values of the adjusted coefficient of determination. Furthermore the value of the natural vacancy rate obtained for Krakow, Wroclaw and Poznan differed quite significantly from the corresponding average value of the market vacancy rate for the studied time range. Therefore, for each of the four analyzed office space markets, we ultimately decided to take the average of the market vacancy rate during the period considered as a long-term vacancy rate, representing the natural vacancy rate for the purposes of the study. The issue of developing an appropriate approach to determine the natural vacancy rate and applying it to the market of modern office space in Poland should be, in our opinion, an interesting subject of further research in the future.

Another issue that should be addressed before attempting to set a hidden vacancy rate is the average rent for all open lease contracts on the market. Such data, if only due to the fact that they are the subject of contractual secrecy, are not published. Hendershott et al. faced with the same problem for the office space market in the City of London, used a five-year moving average to determine the average level of rent for all contracts functioning on the market (HENDERSHOTT et al., 2010, p. 90). This was motivated by the fact that, on the office market examined by them, lease agreements concluded for 25 years with the possibility of changing the rent only upwards every five years were the standard at the time. We have adopted this method for the study of the Polish office space market. Based on consultations with a representative of the Savills consulting company operating on the Polish office space market, we found out that lease contracts in the analyzed cities were usually concluded for five 
years. On this basis, the average rent level for all lease agreements currently in effect on the market was also designated as a moving average over five consecutive years.

\section{Empirical results}

Figure 1 presents inflation adjusted rent rates, the market vacancy rate, the level of the long-term vacancy rate and the hidden vacancy rate determined by the broad and narrow approach, for the Warsaw office space market. Both measures of the hidden vacancy rate are characterized by a similar amplitude and seem to follow the same direction. This is quite evident, especially from the beginning of the examined period until mid-2012. In subsequent periods, this dependence ceases to be so unambiguous. The hidden vacancy rate calculated using the broad approach reached values ranging from around $-27 \%$ in the II quarter of 2006 and in the I quarter of 2016 to nearly $25 \%$ in the II quarter of 2007. In turn, in the narrow approach, the range of fluctuations ranged from -13\% in the IV quarter of 2009 to $42 \%$ in the IV quarter of 2007. Referring to the relation of the natural and market vacancy rate, it is worth invoking Sivitanides, who stated that, when the market vacancy rate is below the level of the natural vacancy rate, then the increase in demand triggers pressure on the increase in rent. On the other hand, when the market vacancy rate exceeds its natural level, then the increase in the market space available translates into a reduction in rent (SIVITANIDES, 1997). The described dependence is confirmed in Figure 1. Fluctuations of the market vacancy rate in relation to the long-term vacancy rate are generally reflected in changes in the real rent. The high values of real rent between the III quarter of 2006 and the III quarter of 2009 were accompanied by a decrease in the market vacancy rate, which, in addition, was clearly below its long-term level. The significant increase in the market vacancy rate recorded after the II quarter of 2012 was confirmed by the successive reduction in real rent rates. An explicit decrease in rent and increase in the market vacancy rate in 2009 were related to the international financial crisis and its consequences, which, at that very time, were becoming visible in the Polish economy in the form of an economic slowdown.

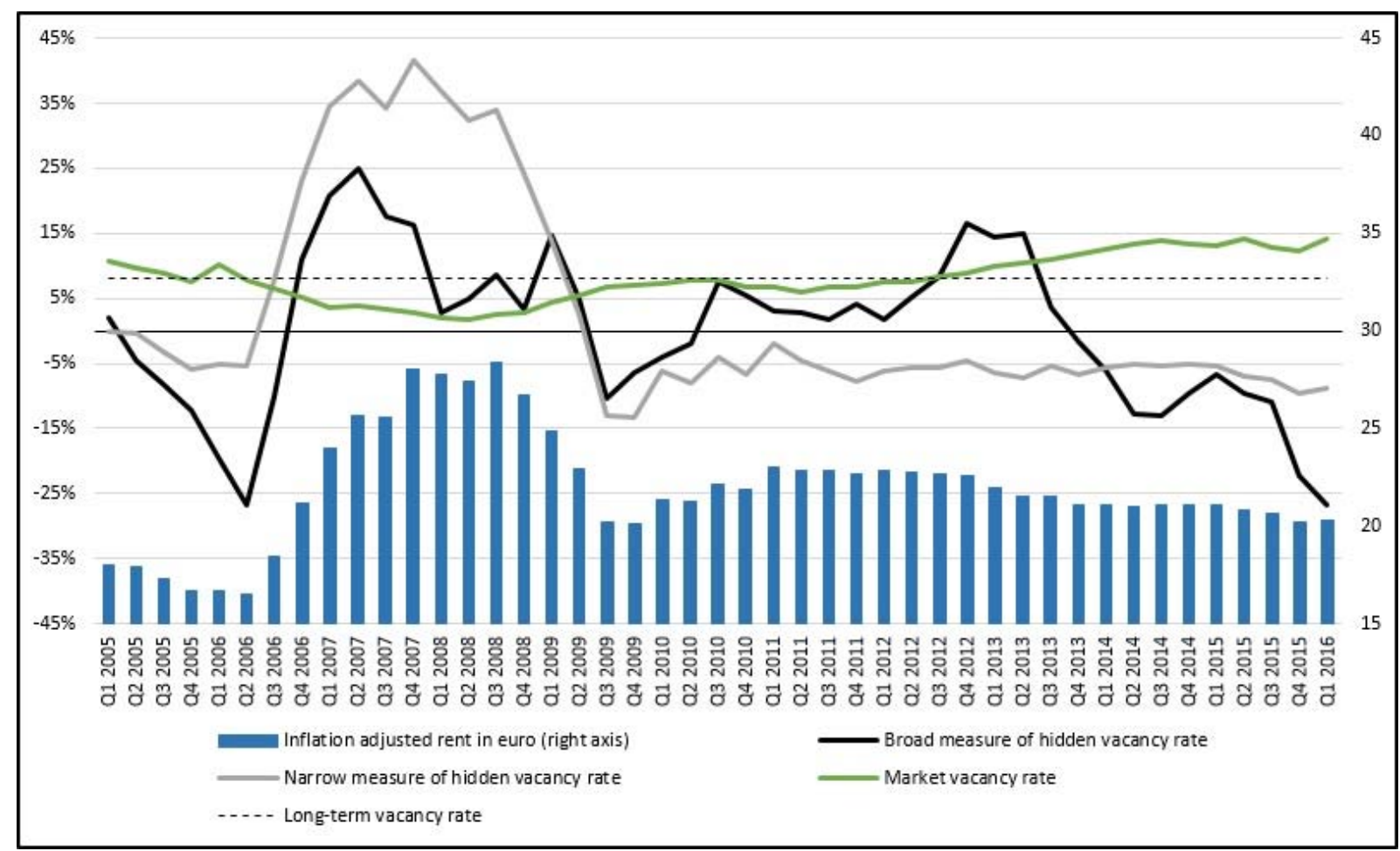

Fig. 1. Hidden vacancy rate determined by a narrow and a broad approach, the market vacancy rate, long-term vacancy rate and inflation adjusted rent in Warsaw, Q1 2005 - Q1 2016. Source: Own study.

Figure 2 presents the hidden vacancy rate determined by a narrow and broad approach of the office space market in Krakow. The relationship between time series of hidden vacancy rates determined by a broad and narrow approach is similar to a negative correlation. The hidden vacancy rate determined by a broad approach showed a significant amplitude of fluctuations, especially in the initial periods of the study, when it dropped from $40 \%$ to $-36 \%$ in the I quarter of 2010 . From the 
beginning of the examined period to the end of 2012, increases / decreases in the market vacancy rate were accompanied by decreases / increases in the hidden vacancy rate calculated according to the broad approach. The hidden vacancy rate in the narrow perspective from the II quarter of 2009 to the I quarter of 2016 remained positive and reached high values, especially until the end of 2013. In the I quarter of 2010, it was nearly $54 \%$. The stabilization of the market vacancy rate of approximately $3-6 \%$ from mid-2012 was accompanied by a decrease in the absolute values of both measures of the hidden vacancy rate. At the end of the analyzed period, both measures were already positive, although they were still heading in opposite directions. Figure 2 indicates that the dependence described by Sivitanides (1997) does not seem to be confirmed in the Krakow office space market. The ongoing decrease in rents was accompanied, since mid-2010, by a steady decline of market vacancy rate. The downward trend in rent did not change even in mid-2012, when the market vacancy rate was already below the long-term average vacancy rate.

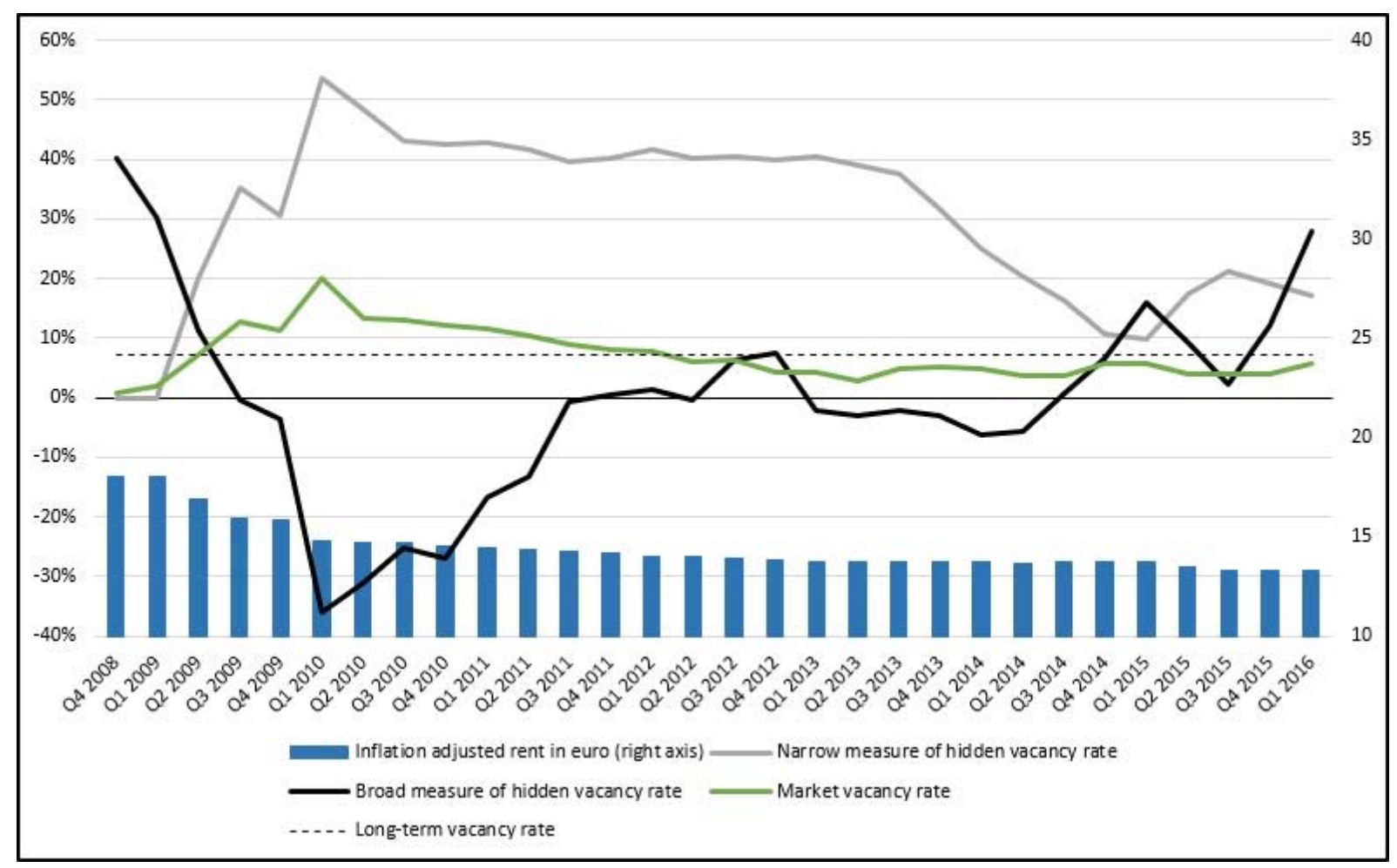

Fig. 2. Hidden vacancy rate determined by a narrow and a broad approach, the market vacancy rate, long-term vacancy rate and inflation adjusted rent in Krakow, Q4 2008 - Q1 2016. Source: Own study.

In Figure 3, which refers to the office space market in Wroclaw, the time series of the hidden vacancy rate in broad and narrow approaches formed almost an opposite reflection of each other and were also characterized by high amplitudes. The range of fluctuations in the hidden vacancy rate in the broad approach ranged from almost $-40 \%$ in the III quarter of 2012 to around $81 \%$ in the IV quarter of 2008. In turn, in the case of the narrow approach, the fluctuation range ranged from $0 \%$ in the IV quarter of 2008 to $57 \%$ in the IV quarter of 2009. The time series of rents and the market vacancy rate presented in Figure 3, as in the case of Krakow, do not confirm the expected dependencies between mutual fluctuations of these two measures.

Figure 4 presents the hidden vacancy rate determined by a narrow and broad approach, inflation adjusted rental rates, the market vacancy rate and the level of the long-term vacancy rate in the office space market in Poznan. The range of fluctuations in the hidden vacancy rate determined by the broad approach ranged from $-19 \%$ in the first quarter of 2015 to $39 \%$ in the first quarter of 2009 . The hidden vacancy rate in the narrow approach reached $0 \%$ in the two initial periods of the study and nearly $40 \%$ in Quarter I of 2010. Although both measures in the case of Poznan were not as close to the mirror image as in Wroclaw, they also definitely did not follow a similar course. In Poznan, as was the case in the two aforementioned cities, the downward trend of rents was independent from fluctuations in market vacancy rate and its relation with the long-term average vacancy level. 


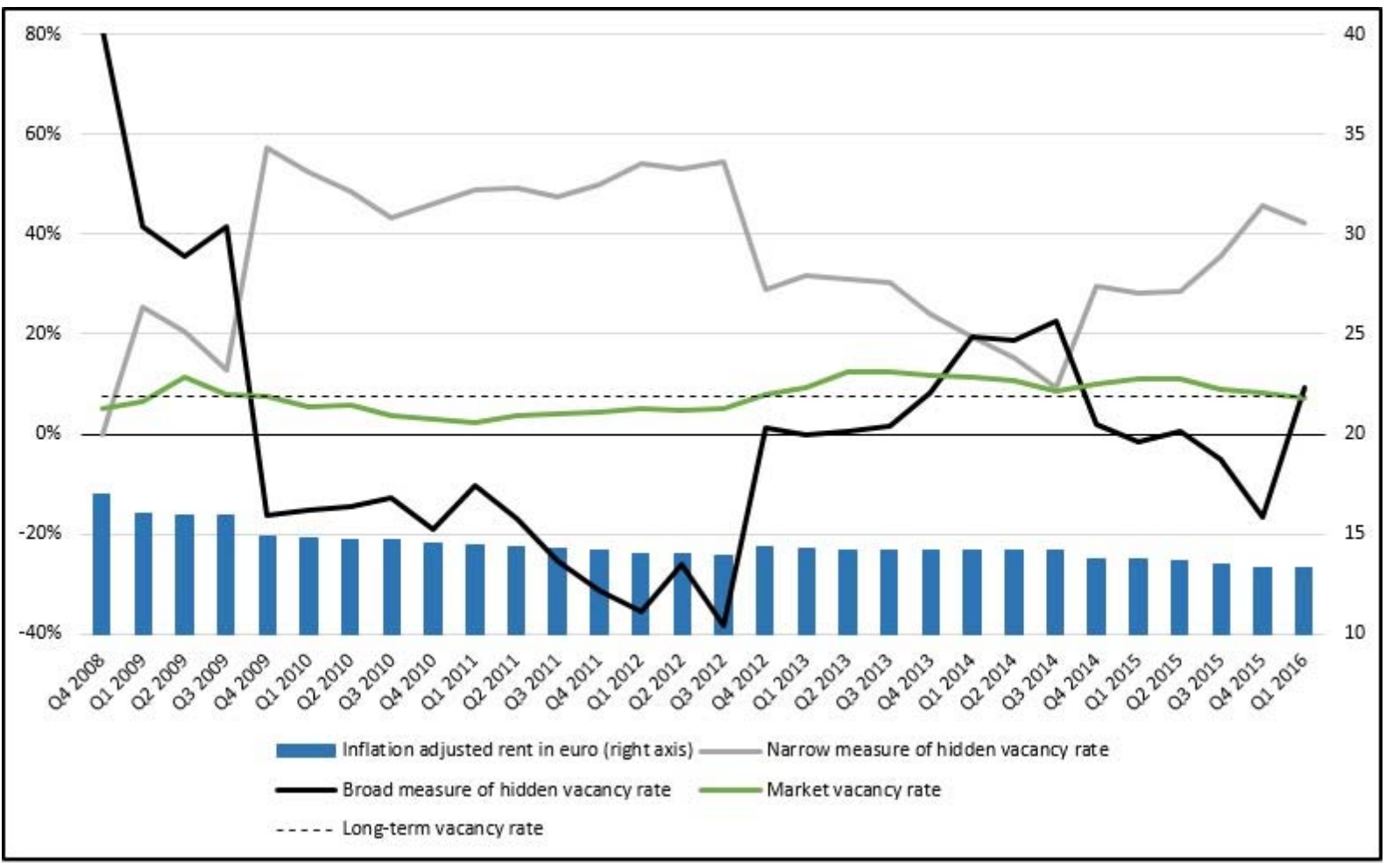

Fig. 3. Hidden vacancy rate determined by a narrow and broad approach, the market vacancy rate, long-term vacancy rate and inflation adjusted rent in Wroclaw, Q4 2008 - Q1 2016. Source: own study.

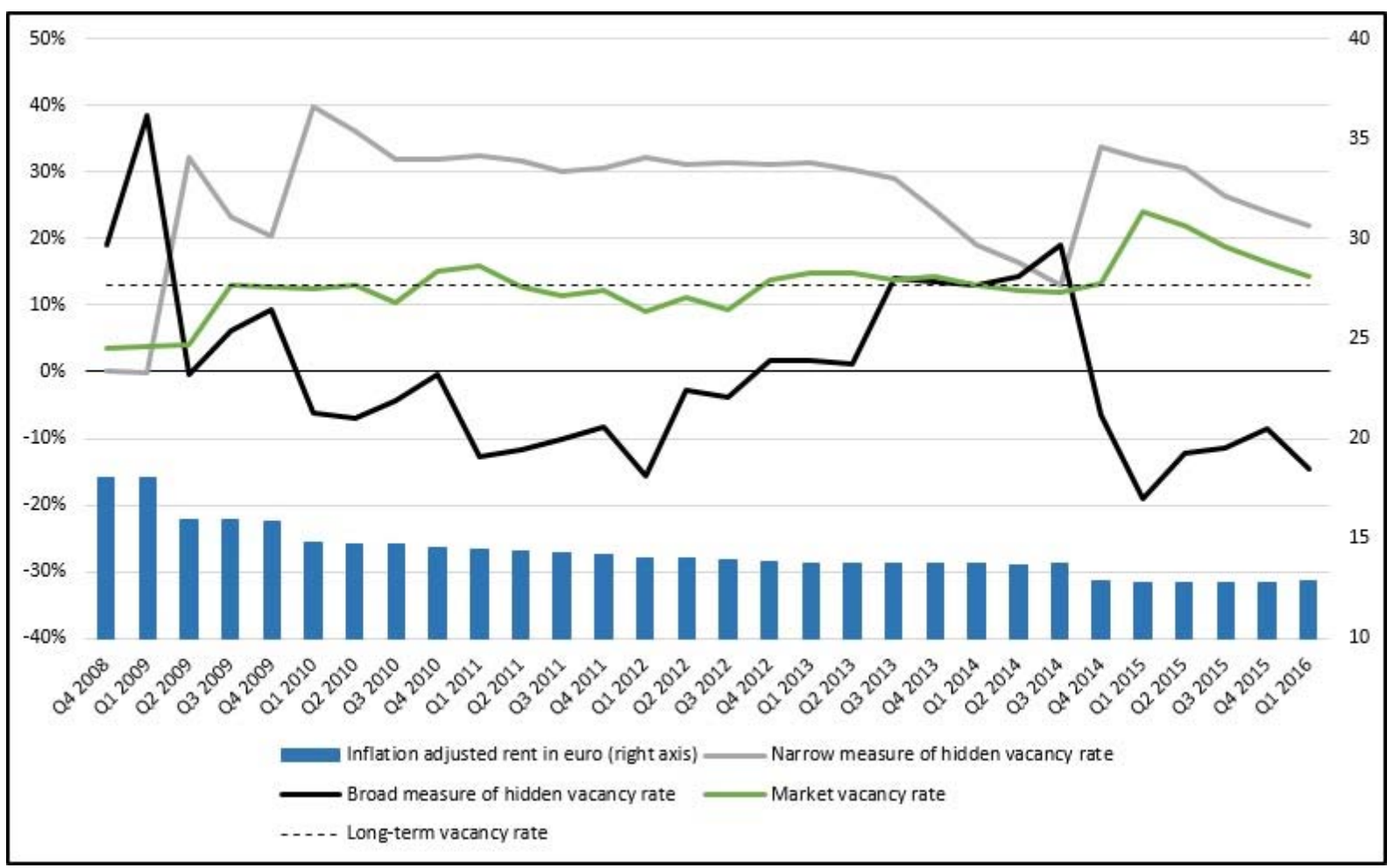

Fig. 4. Hidden vacancy rate determined by a narrow and broad approach, the market vacancy rate, long-term vacancy rate and inflation adjusted rent in Poznan, Q4 2008 - Q1 2016. Source: own study.

\section{Discussion and conclusions}


The conclusions from the research for regional markets in Krakow, Wroclaw and Poznan differ from those for Warsaw. This applies to both the hidden vacancy rate and the fluctuation of rent and the market vacancy rate. In Figure 1 for the Warsaw office market, the relationship between the broad and narrow approach was positive for a much larger part of the period covered by the study, as indicated by Equation (4). In addition, the hidden vacancy rate determined by both the broad and narrow approaches reached high levels when the market rent was at a relatively high level and the market vacancy rate was low. In the opposite situation, when the rent decreased and the market vacancy rate increased exceeding the long-term average, then the value of the hidden vacancy rate declined. Similar results were reported by Englund et al. on the office market in Stockholm. Fluctuations of both measures of the hidden vacancy rate were positively correlated there and slightly lower than in Warsaw (ENGLUND et al., 2008, p. 98). Hendershott et al., who examined fluctuations of the hidden vacancy rate in the City of London, also presented similar conclusions (HENDERSHOTT et al., 2010, p. 90). In view of the above, the conclusion is that the dynamics of the Warsaw office space market - in the period covered by the study - was close to mature markets, even despite the fact that, in terms of the magnitude of office space stock, it is still far from the main western European markets.

The two measures of the hidden vacancy rate for Krakow, Wroclaw and Poznan presented in Figures from 2 to 4 showed fluctuations more or less similar to the negative correlation. This may be due to the steady, downward trend in rent in the three office markets, which affected readings of hidden vacancy determined in the narrow approach. In turn, the high amplitudes that have been recorded in the three cities result, inter alia, from the high values of price elasticity of demand, which ranged from 1.33 to 8.27 for individual markets. The reasons for significant fluctuations in the hidden vacancy rate in the three markets in question should be looked for in their characteristics. Krakow, Wroclaw and Poznan, compared to Warsaw, still remain as markets at a relatively early stage of development. The stock of office space in these three markets at the end of the first quarter of 2016 was at a considerably lower level (Krakow - 801 thousand sq. m., Wroclaw - 725 thousand sq m., Poznan - 391 thousand sq m.) than in the Warsaw market (4.75 million sq. m.). The limited stock of office space on the three regional markets may disrupt supply and demand adjustments. Evidence of this is represented by the fluctuations in rent and the market vacancy rate, whose relationship in these three cities did not follow the pattern shown in literature. When the first office buildings emerged in Krakow, Wroclaw and Poznan, an insufficient quantity of office stock available on the market initially implied high rental rates. As the office space stock gradually increased, rental rates gradually decreased, at the same time heading towards a state of equilibrium. A similar process took place in the second half of the 1990s in Warsaw. Considering these issues, one should be cautious when interpreting the results of the hidden vacancy rate obtained for Krakow, Wroclaw and Poznan.

In recent years, the dynamics of the Polish real estate market has often been the subject of research; in the vast majority of cases, however, such research focused on the housing market. In this respect, there is a form of a research gap in Polish scientific literature when it comes to the market of modern office space. The added value of this paper is primarily an attempt to fill the gap, at least to a certain extent. Secondly, the presented study indicates that there is a difference in the functioning of the office space market in Warsaw and in the main regional markets in Poland. The study showed that the dynamics of the Warsaw office market as regards the hidden vacancy rate, rent and the market vacancy rate is similar to the markets of Western Europe. On the other hand, the fluctuations of these aggregates in the office space markets in Krakow, Wroclaw and Poznan do not follow the pattern presented in the literature.

It should be noted that, in the presented study, we assumed that the equivalent of the natural vacancy rate is the long-term average of the market vacancy rate, which is a certain approximation. As it was indicated above, we chose such a solution due to the fact that the models based on the traditional concept of natural vacancy rate did not give satisfactory results. This points to one of the directions which research on the dynamics of the office space market in Poland should take in the forthcoming future. A proper approach to determining the natural vacancy rate can be used to determine the hidden vacancy rate, but also in the process of identifying turning points of the business cycle in the office market. It can also be used to further compare the dynamics of the office markets in Central and Eastern European countries that have undergone transformation of the economic system, in relation to the markets in Western Europe and the United States characterized by abundant office space stock. 


\section{References}

Adams, Z., \& Füss, R. (2012). Disentangling the Short and Long-Run Effects of Occupied Stock in the Rental Adjustment Process. The Journal of Real Estate Finance and Economics, 44(4), 570-590. https:// doi.org/10.1007/s11146-010-9250-7

Brounen, D., \& Jennen, M. (2009a). Asymmetric Properties of Office Rent Adjustment. The Journal of Real Estate Finance and Economics, 39(3), 336-358. https:// doi.org/10.1007/s11146-009-9188-9

Brounen, D., \& Jennen, M. (2009b). Local Office Rent Dynamics. A Tale of Ten Cities. The Journal of Real Estate Finance and Economics, 39(4), 385-402. https://doi.org/10.1007/s11146-008-9118-2

Bruneau, C., \& Cherfouh, S. (2015). Long-run equilibrium for the Greater Paris office market and short-run adjustments. Journal of Property Research, 32(4), 301-323. https://doi.org/10.1080/09599916.2015.1089310

De Francesco, A. (2008). Time-Series Characteristics and Long-Run Equilibrium for Major Australian Office Markets. Real Estate Economics, 36(2), 371-402. https://doi.org/10.1111/j.15406229.2008.00217.x

Englund, P., Gunnelin, Å., Hendershott, P., \& Söderberg, B. (2008). Adjustment in Property Space Markets: Taking Long-Term Leases and Transactions Costs Seriously. Real Estate Economics, 36(1), 81-109. https://doi.org/10.1111/j.1540-6229.2008.00208.x

Hendershott, P., Lizieri, C., \& MacGregor, B. (2010). Asymmetric Adjustment in the City of London Office Market. The Journal of Real Estate Finance and Economics, 41(1), 80-101. https://doi.org/10.1007/s11146-009-9199-6

Hendershott, P., Lizieri, C., \& Matysiak, G. (1999). The Workings of the London Office Market. Real Estate Economics, 27(2), 365-387. https:// doi.org/10.1111/1540-6229.00777

Hendershott, P., MacGregor, B., \& Tse, R. (2002a). Estimation of the Rental Adjustment Process. Real Estate Economics, 30(2), 165-183. https://doi.org/10.1111/1540-6229.00036

Hendershott, P., MacGregor, B., \& White, M. (2002b). Explaining Real Commercial Rents Using an Error Correction Model with Panel Data. The Journal of Real Estate Finance and Economics, 24(1/2), 59-87. https:// doi.org/10.1023/ A:1013930304732

Ke, Q., \& White, M. (2013). A Tale of Two Chinese Cities: The Dynamics of Beijing and Shanghai Office Markets. Journal of Real Estate Portfolio Management, 19(1), 31-47.

Kośko, M., Osińska, M., \& Stępińska, J. (2007). Ekonometria wspótczesna (Contemporary Econometrics). Wydawnictwo Dom Organizatora, Torun.

McCartney, J. (2010). Predicting Turning Points in the Rent Cycle Using the Natural Vacancy Rate - an Applied Study of Dublin Office Market. Journal of Statistical and Social Inquiry Society of Ireland, 40, 11-32.

McCartney, J. (2012). Short and Long-Run Rent Adjustment in the Dublin Office Market. Journal of Property Research, 29(3), 201-226. https:// doi.org/10.1080/09599916.2012.689990

Mouzakis, F., \& Richards, D. (2007). Panel Data Modelling of Prime Office Rents: A Study of 12 Major European Markets. Journal of Property Research, 24(1), 31-53. https:// doi.org/10.1080/09599910701297713

Sivitanides, P. (1997). The Rent Adjustment Process and the Structural Vacancy Rate in the Commercial Real Estate Market. Journal of Real Estate Research, 13(2), 195-209.

Stevenson, S. (2007). Exploring the Intra-Metropolitan Dynamics of the London Office Market. Journal of Real Estate Portfolio Management, 13(2), 93-98.

\section{Appendix}

Table 2

Results of ADF test for particular time series

\begin{tabular}{|c|c|c|c|c|}
\hline Variable & Test statistic & $1 \%$ Critical value & $5 \%$ Critical value & $10 \%$ Critical value \\
\hline \multicolumn{5}{|c|}{ Warsaw } \\
\hline Rent & -1.571 & -3.621 & -2.947 & -2.607 \\
\hline Employment & -1.943 & -3.621 & -2.947 & -2.607 \\
\hline Stock & -0.904 & -3.621 & -2.947 & -2.607 \\
\hline \multicolumn{5}{|c|}{ Krakow } \\
\hline Rent & -2.853 & -4.343 & -3.584 & -3.230 \\
\hline
\end{tabular}




\begin{tabular}{|c|c|c|c|c|}
\hline Employment & -1.648 & -3.723 & -2.989 & -2.625 \\
\hline Stock & -0.533 & -3.723 & -2.989 & -2.625 \\
\hline \multicolumn{5}{|c|}{ Wroclaw } \\
\hline Rent & -3.490 & -3.723 & -2.989 & -2.625 \\
\hline Employment & -0.962 & -3.723 & -2.989 & -2.625 \\
\hline Stock & 1.352 & -3.723 & -2.989 & -2.625 \\
\hline \multicolumn{5}{|c|}{ Poznan } \\
\hline Rent & -2.958 & -3.723 & -2.989 & -2.625 \\
\hline Employment & 0.181 & -3.723 & -2.989 & -2.625 \\
\hline Stock & -3.562 & -3.723 & -2.989 & -2.625 \\
\hline
\end{tabular}

* The results of the ADF test for time series of rent in Krakow pointed out that it was stationary, therefore we carried out a visual evaluation of this time series, which clearly indicated the occurrence of a downward trend in this time series. Hence, we repeated the ADF test taking into account the trend. The results of such a test indicated the non-stationary nature of this time series.

Source: own study.

Table 3

Results of Johansen test for variables from long-term equations of the error correction models

\begin{tabular}{|c|c|c|c|c|c|c|}
\hline $\begin{array}{l}\text { Number of } \\
\text { cointegrating } \\
\text { vectors }\end{array}$ & $\begin{array}{c}\text { Trace } \\
\text { statistic }\end{array}$ & $\begin{array}{c}5 \% \\
\text { Critical } \\
\text { value } \\
\end{array}$ & $\begin{array}{c}1 \% \\
\text { Critical } \\
\text { value }\end{array}$ & $\begin{array}{l}\text { Maximum } \\
\text { eigenvalue } \\
\text { statistic }\end{array}$ & $\begin{array}{c}5 \% \\
\text { Critical } \\
\text { value }\end{array}$ & $\begin{array}{c}1 \% \\
\text { Critical } \\
\text { value }\end{array}$ \\
\hline \multicolumn{7}{|c|}{ Warsaw } \\
\hline 0 & 44.3545 & 24.31 & 29.75 & 36.4683 & 17.89 & 22.99 \\
\hline 1 & $7.8862^{*, * *}$ & 12.53 & 16.31 & $7.4337^{*, * *}$ & 11.44 & 15.69 \\
\hline 2 & 0.4525 & 3.84 & 6.51 & 0.4525 & 3.84 & 6.51 \\
\hline \multicolumn{7}{|c|}{ Krakow } \\
\hline 0 & 46.8579 & 24.31 & 29.75 & 38.2147 & 17.89 & 22.99 \\
\hline 1 & $8.6432^{*, * *}$ & 12.53 & 16.31 & $7.9269 *, * *$ & 11.44 & 15.69 \\
\hline 2 & 0.7164 & 3.84 & 6.51 & 0.7164 & 3.84 & 6.51 \\
\hline \multicolumn{7}{|c|}{ Wroclaw } \\
\hline 0 & 35.4973 & 24.31 & 29.75 & 26.5840 & 17.89 & 22.99 \\
\hline 1 & $8.9133^{*, * *}$ & 12.53 & 16.31 & $7.9136^{*, * *}$ & 11.44 & 15.69 \\
\hline 2 & 0.9998 & 3.84 & 6.51 & 0.9998 & 3.84 & 6.51 \\
\hline \multicolumn{7}{|c|}{ Poznan } \\
\hline 0 & 38.0607 & 24.31 & 29.75 & 22.5314 & 17.89 & 22.99 \\
\hline 1 & $15.5292^{*}$ & 12.53 & 16.31 & $12.4965^{*}$ & 11.44 & 15.69 \\
\hline 2 & $3.0328^{* *}$ & 3.84 & 6.51 & $3.0328^{* *}$ & 3.84 & 6.51 \\
\hline
\end{tabular}

*one cointegrating vector at $\mathrm{p} 0.01,{ }^{* *}$ one cointegrating vector at $\mathrm{p} 0.05$; Johansen test for two lags.

Source: own study.

Table 4

Long-term equations for ECM Model 1, Model 2, Model 3 and Model 4

\begin{tabular}{|c|c|c|c|c|c|c|}
\hline \multirow[b]{2}{*}{$\begin{array}{l}\text { Independent } \\
\text { variables }\end{array}$} & \multicolumn{3}{|c|}{ Model 1 - Warsaw } & \multicolumn{3}{|c|}{ Model 2 - Krakow } \\
\hline & Coefficient & $\begin{array}{l}\text { Standard } \\
\text { Error }\end{array}$ & t Statistic & Coefficient & $\begin{array}{l}\text { Standard } \\
\text { Error }\end{array}$ & t Statistic \\
\hline Constant & -22.9274 & 2.8759 & $-7.97^{*}$ & 11.0530 & 1.4206 & $7.78^{*}$ \\
\hline Employment & 5.4239 & 0.6028 & $9.00^{*}$ & -1.0543 & 0.3045 & $-3.46^{*}$ \\
\hline Stock & -0.7519 & 0.1067 & $-7.05^{*}$ & -0.2133 & 0.0263 & $-8.12^{*}$ \\
\hline Adjusted $\mathrm{R}^{2}$ & \multicolumn{3}{|c|}{0.6482} & \multicolumn{3}{|c|}{0.8662} \\
\hline $\begin{array}{l}\text { Number of } \\
\text { observation }\end{array}$ & \multicolumn{3}{|c|}{45} & \multicolumn{3}{|c|}{30} \\
\hline
\end{tabular}




\begin{tabular}{|c|c|c|c|c|c|c|}
\hline \multirow{2}{*}{$\begin{array}{c}\text { Independent } \\
\text { variables }\end{array}$} & \multicolumn{3}{|c|}{ Model 3 - Wroclaw } & \multicolumn{3}{c|}{ Model 4 - Poznan } \\
\cline { 2 - 7 } & Coefficient & $\begin{array}{c}\text { Standard } \\
\text { Error }\end{array}$ & t Statistic & Coefficient & $\begin{array}{c}\text { Standard } \\
\text { Error }\end{array}$ & t Statistic \\
\hline Constant & 6.0268 & 1.1844 & $5.09^{*}$ & -1.2621 & 1.3429 & -0.94 \\
\hline Employment & -0.3514 & 0.3772 & -0.93 & 1.4464 & 0.2735 & $5.29^{*}$ \\
\hline Stock & -0.1209 & 0.0651 & $-1.86^{* * *}$ & -0.2626 & 0.0182 & $-14.40^{*}$ \\
\hline Adjusted R & \multicolumn{3}{|c|}{0.6222} & & 0.8822 & 30 \\
\hline $\begin{array}{c}\text { Number of } \\
\text { observation }\end{array}$ & 30 & & & \multicolumn{3}{|c}{} \\
\hline
\end{tabular}

*variable statistically significant

*variable statistically significant at p 0.01 ;

** variable statistically significant at $\mathrm{p} 0.05$;

*** variable statistically significant at $\mathrm{p} 0.1$.

Source: own study. 